\title{
APPLICATION OF MICROSATELLITE GENOTYPING TO THE STUDY OF A RESTRICTED LEISHMANIA INFANTUM FOCUS: DIFFERENT GENOTYPE COMPOSITIONS IN ISOLATES FROM DOGS AND SAND FLIES
}

\author{
LILIANA MONTOYA, MONTSERRAT GÁLLEGO, BÉATRICE GAVIGNET, RENAUD PIARROUX, \\ JEAN-ANTOINE RIOUX, MONTSERRAT PORTÚS, AND ROSER FISA* \\ Laboratory of Parasitology, Universitat de Barcelona, Barcelona, Spain; Santé Environnement Rural Franche-Comté, Université de \\ Franche-Comté, Besançon, France; Institut de Botanique, Université Montpellier I, Montpellier, France
}

Abstract. Leishmania infantum polymorphism was studied by DNA microsatellite analysis of 110 L. infantum stocks (94 from dogs, 15 from sand flies, and 1 from a human visceral case) from a rural leishmaniasis-endemic area (Priorat) in northeastern Spain. Three microsatellites of the eight present in three fragments (internal transcribed spacer, Lm4, and Lm2) of L. infantum nuclear DNA are polymorphic inside the focus, resulting in 17 genotypes. Isolates from dogs and sand flies had different allelic compositions and shared only four genotypes. Microsatellite analysis is useful for $L$. infantum genotyping and epidemiologic tracking. Its application with strains from dogs and vectors in an area endemic for leishmaniasis shows the heterogeneous distribution of L. infantum in hosts living in sympatric conditions.

\section{INTRODUCTION}

Leishmania infantum Nicolle, 1908 is the etiologic agent of human visceral (VL) leishmaniasis and cutaneous (CL) leishmaniasis in the European Mediterranean Basin, where dogs are considered to be the main reservoir. Although the main features of the parasite life cycle have been known for almost a century, several epidemiologic aspects of human and canine leishmaniasis are still poorly understood. Studies using multilocus enzyme electrophoresis (MLEE) in L. infantum, have shown polymorphism that is reflected in insect and host parasite specificity, geographic range, and virulence. ${ }^{1,2}$ However, $L$. infantum strains from different disease-endemic areas of the Mediterranean region show distinct degrees of polymorphism. Some disease-endemic foci in southern France are characterized by low enzymatic polymorphism ${ }^{1}$ in comparison with foci in Catalonia, Spain ${ }^{1,2}$ or foci in southern Spain, ${ }^{3}$ where higher polymorphism has been observed in isolates from a variety of sources (humans, dogs, rats, and sand flies).

A number of methods have proven useful in the analysis of the genetic composition of leishmanial parasite populations. Multilocus enzyme electrophoresis differentiates several zymodemes in the L. infantum complex. ${ }^{1-6}$ Nevertheless, the lack of genetic uniformity detected by random amplified polymorphic DNA in L. infantum zymodemes in southern Spain ${ }^{7}$ and southern France ${ }^{8}$ has highlighted the need for other discriminatory typing methods for epidemiologic studies. Other high-resolution genetic methods, such as selective polymerase chain reaction (PCR), ${ }^{9}$ PCR and sequencing, ${ }^{10}$ or chromosome size polymorphism, ${ }^{11}$ have confirmed the high polymorphism of L. infantum strains.

Microsatellite (MS) DNA sequences are markers used in genetic and population studies of Trypanosomatidae, such as Trypanosoma cruzi $i^{12-14}$ and Leishmania spp., ${ }^{15-18}$ and other protozoa. ${ }^{19,20}$ Microsatellite analyses of three sequences of the L. infantum genome (the internal transcribed spacer [ITS] in the rRNA genes and the Lm2 and Lm4 sequences in the nuclear genome) in strains from several areas of the Mediterranean Basin have shown a high level of polymorphism. ${ }^{21} \mathrm{We}$

* Address correspondence to Roser Fisa, Laboratory of Parasitology, Faculty of Pharmacy, Universitat de Barcelona, Avenida Joan XXIII s/n, 08028 Barcelona, Spain. E-mail: rfisa@ub.edu applied MS analysis to $110 \mathrm{~L}$. infantum stocks, mainly from dogs and sand flies, from a small disease-endemic area in northeastern Spain (Priorat region). This area is characterized by two vector species (Phlebotomus (Larroussius) perniciosus and $P$. (L.) ariasi), ${ }^{22}$ with three zymodemes found in vectors (MON-1, MON-29, and MON-77) and three in dogs (MON-1, MON-28, and MON-77). ${ }^{2,23}$ The application of a highly accurate discriminatory tool to a large number of $L$. infantum sympatric strains from dogs and vectors could provide valuable information about the parasite in this diseaseendemic focus.

\section{MATERIALS AND METHODS}

Study area. The Priorat region is an area in northeastern Spain that produces grapes and hazelnuts. It has an area of $496.20 \mathrm{~km}^{2}$ and a population of 10,000 inhabitants distributed in small rural villages. The region is mostly hilly (250-500 meters above sea level) and is crossed by the Montsant Mountains, which are 1,100 meters above sea level (Figure 1). The climate is meso-Mediterranean, with an average annual temperature of $15^{\circ} \mathrm{C}$ and rainfall of $500-600 \mathrm{~mm}$. The transmission cycle of $L$. infantum occurs mainly in the central and southern areas of the region, which are between 200 and 500 meters above sea level (high endemic area) and have a natural vegetation predominately composed of oak (Quercus ilex) and pine (Pinus halepensis) trees. The prevalence of canine infection is about $20 \%$ in some villages, with an average prevalence of $12.2 \%$ (range $=10-14 \%$ ). Lower seroprevalence rates of canine infection are found in northern part of Priorat, where Quercus ilex ballota, Q. faginae, $Q$. humilis, and Pinus nigra salzmannii are the dominant natural vegetation. ${ }^{23,24}$ Although we have not recorded any cases of $\mathrm{CL}$ during the 20 years that we have been working in this region, the elderly community is aware of CL and some carry oriental sore scars. Seven instances of human leishmaniasis have been reported in this area from 1986 through $2003 .^{25}$

Leishmania infantum stocks. We analyzed 110 Leishmania stocks stored in the Leishmania Cryobank at Universitat de Barcelona in Spain and the International Leishmania Cryobank in Montpellier, France. They were collected between 1986 and 2002 in 15 municipalities in the Priorat region of Spain. Stocks were mainly isolated in those areas considered to be highly endemic for leishmaniasis (Figure 1). Ninety-four 


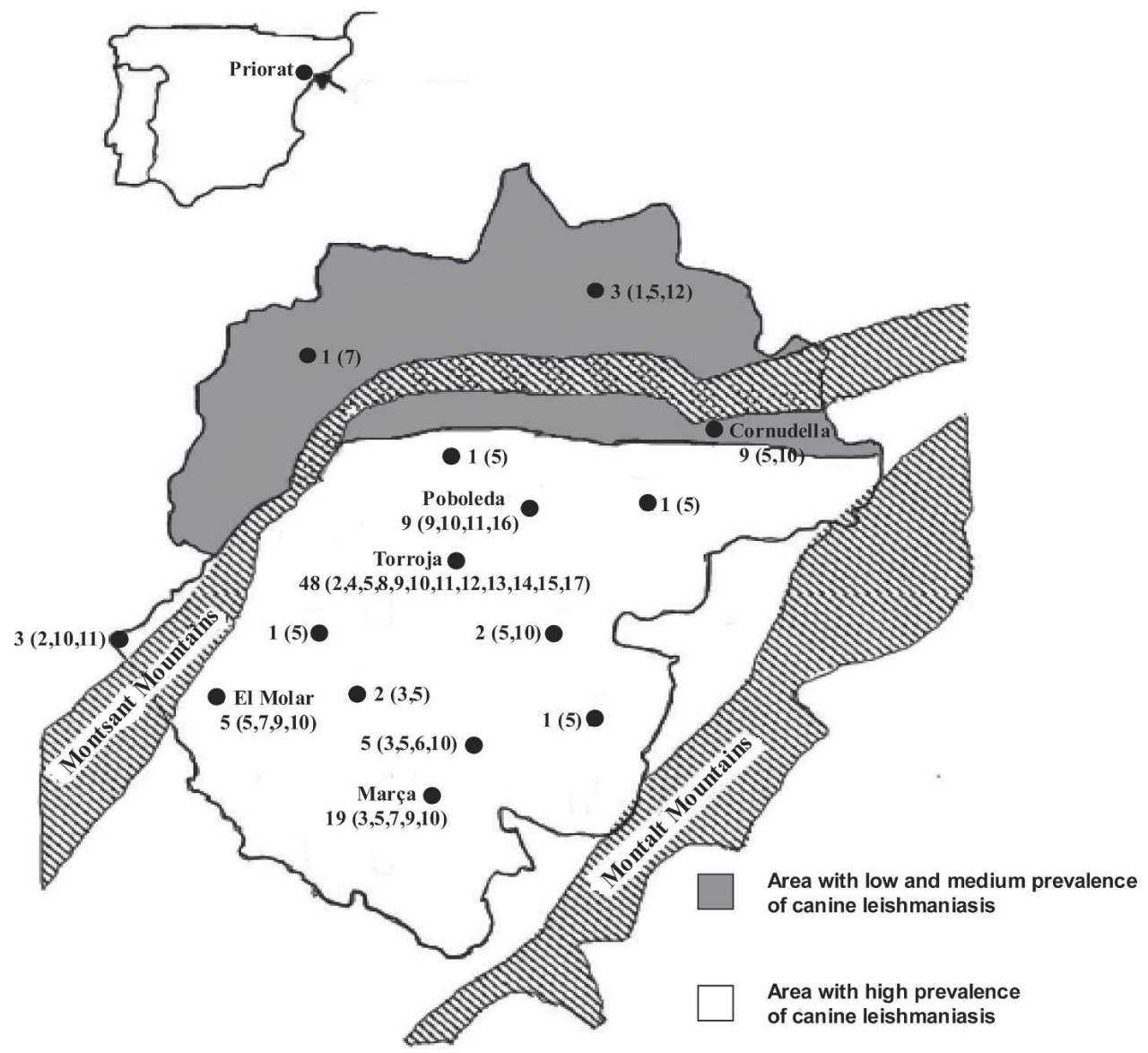

FIgURE 1. Map of the Priorat region of Spain. Dots represent municipalities, with the number of stocks isolated, and values in parentheses are multilocus genotypes observed.

stocks were isolated from dogs (34 symptomatic dogs and 60 asymptomatic dogs) as previously defined, ${ }^{23} 15$ from sand flies (10 from $P$. ariasi and 5 from $P$. perniciosus) from two localities (Torroja del Priorat and Poboleda), ${ }^{26}$ and 1 from a human (a child with VL). ${ }^{2}$ Stocks were isolated from blood (buffy coat), bone marrow, popliteal lymph node aspirates, and skin in dogs, from intestines in sand flies, and from bone marrow in the child. They were cultured in Schneider's insect medium and/or in Novy-McNeal-Nicolle's medium and incubated at $24-26^{\circ} \mathrm{C}$. Promastigotes were cryopreserved in liquid nitrogen with dimethyl sulfoxide or glycerol.

Microsatellite analysis. Isolation of DNA. One cryovial from each stock was used for isolation of DNA. The promastigotes were quickly thawed, the pellet was washed in $500 \mu \mathrm{L}$ of phosphate-buffered saline, suspended in $100 \mu \mathrm{L}$ of sterile distilled water, and lysed by heating at $100^{\circ} \mathrm{C}$ for 20 minutes with $400 \mu \mathrm{L}$ of a mixture of $1 \%$ Tween 20 (Sigma, St, Louis, MO), 1\% Nonidet P-40 (Sigma), and 20\% Chelex resin (BioRad Laboratories, Hercules, CA) in sterile distilled water. The mixture was then centrifuged at $12,000 \times g$ for 10 minutes at room temperature. Amplification of the supernatant by PCR was either performed immediately or after storage at $-20^{\circ} \mathrm{C}$.

Amplication by PCR. Eight MSs were studied: MS-AT, MS-TA $\left(\mathrm{TA}^{1}\right)$, and MS-G in the ITS region of the rRNA genes; MS-TG and the incomplete MS-TG-CG-TG in the Lm2 sequence; and MS-A, MS-T, and MS-TA $\left(\mathrm{TA}^{2}\right)$ in the
Lm4 sequence. Primers and PCR conditions were as described. ${ }^{21}$ We used primer Lm4A6 (5'-TGTGGTCTCACTAGCTTTCAATTC-3') instead of Lm4A1 and primer Lm2A4 (5'-GTGAAGGGCAACACGAAAAA-3') instead of Lm2A3. The PCRs were performed in an automated thermocycler PTC 200 DNA Engine (MJ Research, Waltham, MA) with annealing temperatures of $52^{\circ} \mathrm{C}$ for ITS and $63^{\circ} \mathrm{C}$ for Lm2 and Lm4 fragments.

DNA sequencing. The PCR products were purified using the QIAquick PCR purification kit (Qiagen, Valencia, CA) and sequenced in both directions using the BigDye ${ }^{\circledR}$ Terminator version 1.1 Cycle Sequencing Kit (Applied Biosystems, Foster City, CA) and the capillary electrophoresis DNA sequencer ABI Prism 3700 (Applied Biosystems) following the manufacturer's instructions. The same primers were used for sequencing reactions as for PCR amplifications.

Isoenzyme analysis. Isolates were characterized by isoenzyme electrophoresis using a panel of 13 enzymes (covering 15 enzymatic systems): malate dehydrogenase (MDH), EC 1.1.1.37; malic enzyme (ME), EC 1.1.1.40; isocitrate dehydrogenase (ICD), EC 1.1.1.42; 6-phosphogluconate dehydrogenase (6PGD), EC 1.1.1.44; glucose-6-phosphate dehydrogenase (G6PDH), EC 1.1.1.49; glutamate dehydrogenase (GLUD), EC 1.4.1.3; NADH diaphorase (DIA), EC 1.6.2.2; purine nucleoside phosphorylases 1 and 2 (NP1 and NP2), EC 2.4.2.1; glutamate-oxaloacetate transaminases 1 and 2 (GOT1 and GOT2), EC 2.6.1.1; phosphoglucomutase (PGM), EC 
5.4.2.2; fumarate hydratase (FH), EC 4.2.1.2; mannose phosphate isomerase (MPI), EC 5.3.1.8; and glucose phosphate isomerase (GPI), EC 5.3.1.9. ${ }^{27}$

Statistical analysis. FSTAT version 2.9.3.2. was used to calculate allele frequencies at each locus. ${ }^{28}$ Dendrograms were produced using the NTSYS program, version 1.80 (Exeter Software, Setauket, NY). Similarities were calculated using the Jaccard coefficient and clustered through the unweighted pair-group method for arithmetic averages (UPGMA) algorithm. ${ }^{29}$

\section{RESULTS}

Microsatellites and multilocus genotypes (MLGs). After amplification of three regions of the nuclear DNA of 110 stocks of $L$. infantum complex isolated from the Priorat focus, the sequencing study detected 17 alleles at the 8 MS examined. Only three MS were relevant by virtue of being polymorphic with 3 (MS-G), 4 (MS-TA ${ }^{2}$ ), and 5 alleles (MS-TG) (Table 1). Seventeen MLGs were identified on the basis of allelic combinations and arbitrarily coded from 1 to 17 (Table 2). Half of the stocks analyzed corresponded to MLG-5 and MLG-10.

Spatial distribution of genotypes of $\boldsymbol{L}$. infantum. The spatial distribution of MLGs was related to their frequency, with the most frequent MLGs (MLG-5 and MLG-10) found throughout the study area (Figure 1). In regions with low rates of seroprevalence, 13 stocks were isolated from dogs, corresponding to 5 genotypes. Eight of the nine stocks isolated from dogs over a period of 13 years (from 1989 through 2002) in one locality (Cornudella del Montsant) belonged to the same genotype (MLG-5). The remaining four stocks isolated from other places in this area of low endemicity had distinct genotypes. Clustering, such as that observed in Cornudella, was not observed in any localities in the area with high rates of seroprevalence (Table 3 ).

Host structuring. Allelic compositions differed between dog and sand fly isolates. The most striking difference was

TABLE 1

Allelic frequencies at eight microsatellites in the Leishmania infantum population studied in the Priorat region of Spain*

\begin{tabular}{|c|c|c|c|c|c|c|c|}
\hline \multirow[b]{2}{*}{ Locus } & \multirow[b]{2}{*}{ Allele $\dagger$} & \multicolumn{2}{|c|}{ All stocks } & \multicolumn{2}{|c|}{ Dog stocks } & \multicolumn{2}{|c|}{ Sand fly stocks } \\
\hline & & N (110) & $\mathrm{F}$ & N (94) & $\mathrm{F}$ & N (15) & $\mathrm{F}$ \\
\hline $\mathrm{AT}$ & 5 & 110 & 1 & 94 & 1 & 15 & 1 \\
\hline $\mathrm{TA}^{1}$ & 5 & 110 & 1 & 94 & 1 & 15 & 1 \\
\hline \multirow[t]{3}{*}{ G } & 7 & 101 & 0.918 & 94 & 1 & 6 & 0.400 \\
\hline & 8 & 1 & 0.009 & 0 & 0 & 1 & 0.067 \\
\hline & 9 & 8 & 0.073 & 0 & 0 & 8 & 0.533 \\
\hline \multirow[t]{5}{*}{ TG } & 23 & 21 & 0.191 & 12 & 0.128 & 8 & 0.533 \\
\hline & 24 & 18 & 0.164 & 14 & 0.149 & 4 & 0.267 \\
\hline & 25 & 59 & 0.536 & 58 & 0.617 & 1 & 0.067 \\
\hline & 26 & 1 & 0.009 & 1 & 0.011 & 0 & 0 \\
\hline & 27 & 11 & 0.100 & 9 & 0.96 & 2 & 0.133 \\
\hline TG-CG-TG & $8-5$ & 110 & 1 & 94 & 1 & 15 & 1 \\
\hline A & 10 & 110 & 1 & 94 & 1 & 15 & 1 \\
\hline $\mathrm{T}$ & 9 & 110 & 1 & 94 & 1 & 15 & 1 \\
\hline \multirow[t]{4}{*}{$\mathrm{TA}^{2}$} & 10 & 6 & 0.055 & 4 & 0.043 & 2 & 0.133 \\
\hline & 11 & 42 & 0.382 & 40 & 0.426 & 1 & 0.067 \\
\hline & 12 & 54 & 0.491 & 46 & 0.489 & 8 & 0.533 \\
\hline & 13 & 8 & 0.073 & 4 & 0.043 & 4 & 0.267 \\
\hline
\end{tabular}

$* \mathrm{~N}=$ number of stocks; $\mathrm{F}=$ frequency.

$\dagger$ Number of repeats.

\$ Includes one human stock. observed at MS-G, which was polymorphic in the 15 stocks taken from sand flies (MS-G $\mathrm{G}_{7}$ [6 of 15], MS-G $\mathrm{G}_{8}$ [1 of 15], and MS- $\mathrm{G}_{9}[8$ of 15]) but monomorphic in the 94 dog isolates $\left(\mathrm{MS}-\mathrm{G}_{7}\right)$. Twelve MLGs were identified in canine stocks and 9 MLGs were identified in those from sand flies (Table 2). Forty-two canine stocks were isolated in those localities where infected sand flies were also captured (Torroja and Poboleda). The distribution of genotypes in isolates from dogs and sand flies was heterogeneous (Table 4); statistically significant differences were only observed for MLG-10 because of the low number of strains with other MLGs. The reservoir and vector shared only four genotypes and no stock from the most prevalent genotype in dogs (MLG-10) was isolated in sand flies $(P<0.05)$. In Torroja, 37 canine stocks were obtained from 1986 through 2002 and 11 sand fly stocks were obtained from 1986 through 1992 without any temporal clustering in genotypes from either host.

Most animals had no external signs of leishmaniasis when the parasite was isolated. The numbers and distribution of genotypes of stocks from asymptomatic and symptomatic animals was similar (Table 2). Consequently, no association was observed between MLGs and the virulence of the strain, which was expressed as the clinical status of the animal. However, we did not perform a statistical analysis because of the low numbers of stocks of each genotype. Five stocks were isolated from the skin of dogs in Torroja and identified as MLG-8, MLG-9, MLG-10, MLG-11, and MLG-12, all of which were also identified in stocks of visceral origin.

Correspondence of microsatellites and MLEE by clustering analysis. Microsatellite analysis of $110 \mathrm{~L}$. infantum stocks isolated in the Priorat region identified 17 MLGs, in contrast to the 4 zymodemes identified by isoenzyme analyses of 100 of those stocks (Table 2). A dendrogram using the Jaccard index and the UPGMA algorithm enabled stocks to be clustered by microsatellites into four groups, each one featuring a different representation of zymodemes (Figure 2). Groups A and B contained stocks belonging to zymodeme MON-1 (70 stocks) and the related MON-77 (9 stocks). Group C showed a heterogeneous composition: MON-1 (3 stocks), MON-28 (6 stocks), MON-29 (4 stocks), and MON-77 (2 stocks). Group $\mathrm{D}$ contained isolates belonging to the two zymodemes: MON29 (5 stocks) and MON-1 (1 stock).

\section{DISCUSSION}

Few studies have been conducted to isolate and characterize sympatric strains of $L$. infantum from vertebrates and vectors in restricted foci, which explains why the epidemiologic cycle of most zymodemes is unknown. ${ }^{2}$ In the present study, we applied microsatellite analysis to L. infantum stocks from dogs and sand flies from a small disease-endemic area in Catalonia in northeastern Spain characterized by two vector species ( $P$. perniciosus and $P$. ariasi) and four $L$. infantum zymodemes. $^{2,22,23}$

Studies of the molecular epidemiology of Leishmania species demonstrate that similar types tend to be proximal because of aggregation in space or time. The polymorphism of L. (Viannia) braziliensis from several areas in Brazil indicates that most genotypes are specific to certain geographic areas. ${ }^{30}$ In the Mediterranean region, the distributions of L. infantum strains in southern France characterized by chromosomal 
TABLE 2

Multilocus genotypes (MLGs) and zymodemes in 110 Leishmania infantum stocks from dogs and sand flies from the Priorat region of Spain*

\begin{tabular}{|c|c|c|c|c|c|c|c|c|c|c|}
\hline \multirow[b]{3}{*}{ MLG $\dagger$} & & & & & & \multicolumn{3}{|r|}{ Dog stocks } & \multirow{2}{*}{\multicolumn{2}{|c|}{ Sand fly stocks }} \\
\hline & \multicolumn{3}{|c|}{ Microsatellite末 } & \multicolumn{2}{|c|}{ All stocks§ } & \multicolumn{2}{|c|}{ No. } & \multirow[b]{2}{*}{ Zymodemes } & & \\
\hline & G & TG & TA & No. & $\mathrm{F}$ & A & $\mathrm{S}$ & & No. & Zymodemes \\
\hline 1 & 7 & 23 & 10 & 1 & 0.01 & 1 & - & ND & - & - \\
\hline 2 & 7 & 25 & 10 & 3 & 0.03 & 1 & 2 & MON-1 & - & - \\
\hline 3 & 7 & 23 & 11 & 9 & 0.08 & 6 & 2 & MON-1, MON-28, MON-77, ND & - & - \\
\hline 4 & 7 & 24 & 11 & 2 & 0.02 & 1 & 1 & MON-1, ND & - & - \\
\hline 5 & 7 & 25 & 11 & 26 & 0.24 & 18 & 7 & MON-1, ND & 1 & MON-1 \\
\hline 6 & 7 & 26 & 11 & 1 & 0.01 & 1 & - & MON-1 & - & - \\
\hline 7 & 7 & 27 & 11 & 4 & 0.04 & 3 & 1 & MON-1 & - & - \\
\hline 8 & 7 & 23 & 12 & 4 & 0.04 & 1 & 2 & MON-1, MON-77, ND & 1 & MON-29 \\
\hline 9 & 7 & 24 & 12 & 10 & 0.09 & 5 & 3 & MON-1, MON-77, ND & 2 & MON-1, MON-77 \\
\hline 10 & 7 & 25 & 12 & 30 & 0.27 & 18 & 12 & MON-1, MON-77, ND & - & - \\
\hline 11 & 7 & 27 & 12 & 7 & 0.06 & 4 & 1 & MON-1 & 2 & MON-1 \\
\hline 12 & 7 & 24 & 13 & 4 & 0.04 & 1 & 3 & MON-1, MON-77 & - & - \\
\hline 13 & 8 & 23 & 10 & 1 & 0.01 & - & - & - & 1 & MON-29 \\
\hline 14 & 9 & 23 & 10 & 1 & 0.01 & - & - & - & 1 & MON-29 \\
\hline 15 & 9 & 23 & 12 & 3 & 0.03 & - & - & - & 3 & MON-29 \\
\hline 16 & 9 & 23 & 13 & 2 & 0.02 & - & - & - & 2 & MON-1, MON-29 \\
\hline 17 & 9 & 24 & 13 & 2 & 0.02 & - & - & - & 2 & MON-29 \\
\hline
\end{tabular}

size $^{11}$ or from southern Spain characterized by random amplified polymorphic DNA analysis ${ }^{7}$ were also found to be related to their geographic origin. This geographic aggregation was also observed in the present study and became evident through the low number of polymorphic microsatellites and their low variability, particularly in comparison with the variability observed in stocks from broader areas analyzed using the same methods ${ }^{21}$ (Montoya L and others, unpublished data).

Several MLGs were widely distributed and overrepresented (MLG-5 and MLG-10) in the Priorat region. Ten L. infantum MLGs found in the focus have not been described previously in other disease-endemic foci in the Mediterranean region, ${ }^{21}$ possibly because of the low numbers of stocks from dogs and sand flies typed from other geographic areas. In all 10 cases, since these genotypes were underrepresented, they are unlikely to be related to a diseaseendemic situation. Multilocus genotype polymorphism was observed across the region, particularly in localities situated in the area of high endemicity, which may be related to the ancient origin of this focus and the dispersion of infected animals. Nevertheless, the homogeneous cluster observed in dog stocks from Cornudella, a locality situated in an area with

TABLE 3

Multilocus genotypes (MLGs) in Leishmanina infantum stocks from dogs in several localities in the Priorat region of Spain*

\begin{tabular}{lcl}
\hline \multicolumn{1}{c}{ Location } & No. ot stocks & \multicolumn{1}{c}{ MLGs (no. of isolates) } \\
\hline Torroja & 37 & $\mathbf{2}(2), \mathbf{4}(2), \mathbf{5}(3), \mathbf{8}(3), \mathbf{9}(5), \mathbf{1 0}(18), \mathbf{1 1}(1)$, \\
& & $\mathbf{1 2}(3), \mathbf{5}(4), \mathbf{7}(2), \mathbf{9}(1), \mathbf{1 0}(5)$ \\
Marça & 19 & $\mathbf{5}(8), \mathbf{1 0}(1)$ \\
Cornudella & 9 & $\mathbf{5}(1), \mathbf{7}(1), \mathbf{9}(2), \mathbf{1 0}(1)$ \\
El Molar & 5 & $\mathbf{1 0}(2), \mathbf{1 1}(3)$ \\
Poboleda & 5 & $\mathbf{1}(1), \mathbf{2}(1), \mathbf{3}(1), \mathbf{5}(9), \mathbf{6}(1), \mathbf{7}(1), \mathbf{1 0}(3)$, \\
Other & 19 & $\mathbf{1 1}(1), \mathbf{1 2}(1)$ \\
& &
\end{tabular}

* MLG code is in bold low endemicity, is quite remarkable. The repeated isolation of the same MLG in several dogs over a 13-year period in this locality could be associated with the stability of $\mathrm{MSs}^{16,21}$ and the isolation of the microfocus of infection within the area of low transmission. ${ }^{23}$

Most studies on Leishmania have been performed on strains from the vertebrate host (humans or reservoir animals) that were compared across geographic regions. Differences in types composition in L. infantum populations from humans and dogs have been repeatedly found using MLEE. ${ }^{2,3,31-33}$

In the present study, nine stocks from sand flies were belonged to five distinct genotypes not found in dogs. This is consistent with previous MLEE results, which identified several strains such as MON-29, ${ }^{22,23}$ which is not found in dogs in the focus, and are related to $\mathrm{CL}$ in immunocompetent patients in Catalonia. ${ }^{34}$ Sand flies were captured in two neighboring villages (Torroja and Poboleda) separated by only 4 $\mathrm{km}$, where 42 stocks from dogs were also isolated. A similar situation of Leishmania spp. strains isolated from vectors being distinct from those isolated from the vertebrate host has been found in Morocco ${ }^{35,36}$ and in southern Spain. ${ }^{3}$

The polymorphism of a given Leishmania species in natural populations has been related to the number of sand fly vector(s) and/or animal reservoir(s) involved in the transmission cycle of the parasites. ${ }^{30}$ The simultaneous transmission of $L$. infantum by $P$. perniciosus and $P$. ariasi in the Priorat re-

TABLE 4

Multilocus genotypes (MLGs) of Leishmania infantum stocks from dogs and sand flies in Torroja and Poboleda, Spain

\begin{tabular}{llllllrrrrrrrr}
\hline & \multicolumn{11}{c}{ MLG code } \\
\cline { 2 - 12 } \multicolumn{1}{c}{ Stock } & 2 & 4 & 5 & 8 & 9 & 10 & 11 & 12 & 13 & 14 & 15 & 16 & 17 \\
\hline Dog (42) & 2 & 2 & 3 & 3 & 5 & 20 & 4 & 3 & 0 & 0 & 0 & 0 & 0 \\
Sand fly (15) & 0 & 0 & 1 & 1 & 2 & 0 & 2 & 0 & 1 & 1 & 3 & 2 & 2 \\
\hline
\end{tabular}




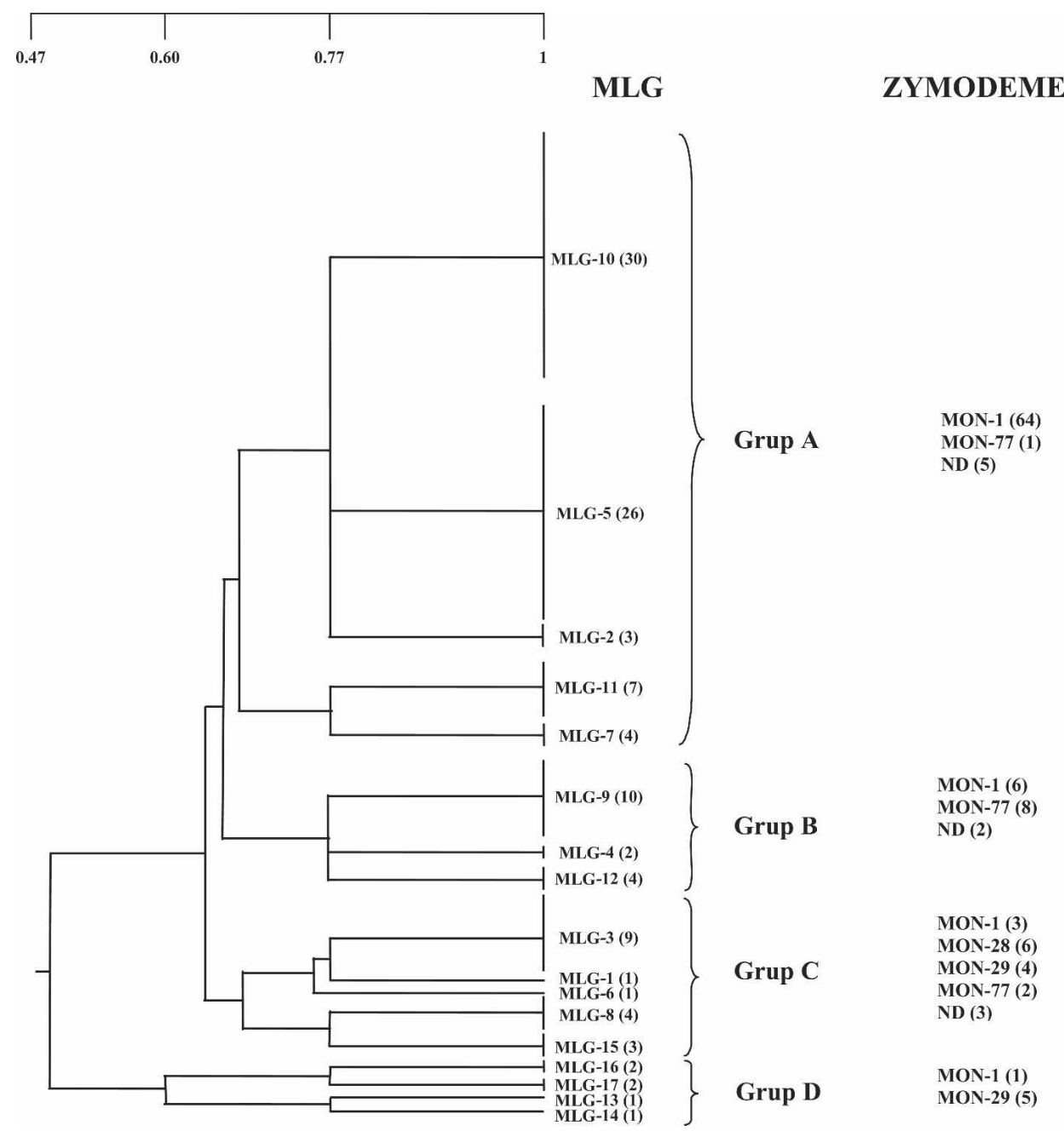

FIGURE 2. Unweighted pair-group method for arithmetic averages dendrogram generated from microsatellite analysis of 110 stocks of Leishmania infantum based on the Jaccard index. Results of analysis by multilocus enzyme electrophoresis (MLEE) are also indicated. Values in parentheses are the number of stocks. MLG = multilocus genotype; ND = stocks on which MLEE was not performed.

gion $^{22,26}$ is not reflected in differences in MLG distribution between the two sand fly species. Both are vectors of at least two MLG found in dogs.

With regards to their human origin, seven human cases of leishmaniasis have been reported in the Priorat area during 1986-2003, ${ }^{25}$ but there have been no acknowledged cases in Torroja, where most of the infected sand flies were captured. The possibility of sand flies being infected by blood meals from one affected person, as might be suspected if one only considers the isoenzyme analysis (strains identified as zymodeme MON-29), can be rejected by the polymorphism detected in MLG, which indicates the existence of more than one origin. It is doubtful that several undetected human cases of CL in a village as small as Torroja were the source of these strains. Thus, the possibility of human cryptic infections, as detected in other neighboring areas such as the Balearic Islands ${ }^{37}$ and southern France, ${ }^{38}$ must also be considered.

There is little support for a hypothesis connecting the existence of these strains in sand flies to dermotropic strains from dogs. The five typed isolates from dog skin were all from Torroja. Stocks were obtained during a study performed on all the dogs from this village in which samples of popliteal lymph node, bone marrow, skin lesions, and healthy skin were cultured. None of the stocks analyzed matched the MLGs detected in sand flies or zymodeme MON-29.

Foxes are also considered a potential wild canine reservoir for leishmaniasis in southern Europe. ${ }^{39-41}$ In the Priorat focus, the seroprevalence of antibodies to Leishmania in foxes is similar to that of dogs..$^{23,42}$ Moreover, the relatively low population of this animal and their wild habitats raise doubts as to their possible role as a reservoir of genotypes only found in vectors, especially because almost all infected sand flies were caught inside villages. The number of animal species, other than dogs, infected by L. infantum in the western part of the Mediterranean region is increasing and in recent years cutaneous lesions caused by this parasite have been diagnosed in cats and horses. ${ }^{43-45}$ Infected rodents have also been repeatedly reported. ${ }^{46,47}$ The results of parasitologic analysis (direct examination and culture) of several samples (blood, spleen, liver, bone marrow, and heart) of eight seropositive rodents captured in Torroja were negative..$^{23}$

The possibility of original mixed infections of L. infantum, both in sand flies and vertebrate hosts, and the bias caused by culturing the parasite requires consideration. ${ }^{48}$ Two Leishma- 
nia species in the sand fly Lutzomyia ovallesi were reported, ${ }^{49}$ one of which was selected in the vertebrate host. In addition, two L. infantum strains have been demonstrated in dogs 50 and humans, ${ }^{51,52}$ one of which was selected in the culture. Five MLGs have been identified in $14 \mathrm{~L}$. infantum isolates from repeated VL episodes, all from one patient coinfected with human immunodeficiency virus, which supports the existence of a mixed infection (Montoya $\mathrm{L}$ and others, unpublished data). We believe that strains with MLGs exclusively found in vectors have no unique origin and all the hypotheses discussed may play a role.

The dendrogram constructed from MS analyses allowed stocks to be clustered into four groups. Almost all stocks in groups $\mathrm{A}$ and $\mathrm{B}$ (8 MLG) corresponded to MON-1 (70 stocks) and those in group D (4 MLG) to MON-29 (5 stocks). Group C (5 MLG) was more heterogeneous, with stocks belonging to all four zymodemes (MON-1, MON-28, MON-29, and MON-77). Remarkably, most stocks included in groups $\mathrm{C}$ and $\mathrm{D}$ were isolated from sand flies. Leishmania infantum MON-1 is the most common and extensive zymodeme found ${ }^{1}$ as a result of a great number of stocks from hosts from distinct geographic origins and pathologic situations having been studied. The application of several genetic markers to MON-1 strains demonstrated a large polymorphism within this zymodeme, and that the differences between two L. infantum MON-1 stocks is sometimes greater than that between different zymodemes or even between L. infantum and L. donovani. ${ }^{8}$ It is therefore not surprising that several MON-1 stocks from the Priorat region are found in all the MLG groups in the microsatellite dendrogram (12 MLG), although with a very skewed distribution. Such a situation may also be found for other zymodemes if a large enough number of stocks are studied, as we detected in the MON-29 zymodeme (6 MLG). Our work agrees with the UPGMA phenograms established with a microsatellite analysis for $L$. infantum stocks from different geographic areas that found a large cluster mainly composed of strains belonging to zymodeme MON-1, with one MON-77 and one MON-108, and a second cluster with nonMON-1 strains. ${ }^{18}$ It also corresponds with the idea of a high polymorphism inside the MON-1 zymodeme, when more discriminating techniques are used, even if strains from a small physical area are included in the study.

Our results confirm that MS analysis is a powerful tool for L. infantum strain typing and epidemiologic tracking studies. In the present study, application of MS analysis to L. infantum complex stocks reinforced a previous observation using MLEE analysis on the heterogeneity of strains from vectors and vertebrates in the same focus, the cause of which is unknown. However, the application of MS analysis and other highly discriminatory typing methods on cloned and sympatric strains from vectors and vertebrates (VL, CL, and cryptic infections in humans, dogs, and other reservoirs) is necessary to enhance our understanding of the population dynamics and epidemiology of Mediterranean leishmaniasis.

Received June 21, 2006. Accepted for publication December 14, 2006

Acknowledgments: Many of the Leishmania stocks studied were isolated during summer campaigns in collaboration with researchers from the Laboratoire d'Écologie Médicale (Montpellier, France). We acknowledge their help, particularly the assistance of Drs. E. Guilvard, G. Moreno and F. Pratlong in the isolation of stocks from sand flies and isoenzyme identification. We thank Drs. J. G. Lorén, M. C. Fusté, and M. Farfán (Laboratory of Microbiology, Facultat de Farmàcia, Universitat de Barcelona, Barcelona) for genetic analysis; and Dr. G. Cuny (Laboratoire de Recherches et de Coordination sur les Trypanosomes, Montpellier, France) and Dr. P. Darlu (Laboratoire de Génétique Épidémiologique et Structure des Populations Humaines, Villejuif, France) for valuable comments and suggestions. We also thank the inhabitants of the Priorat region for their collaboration in fieldwork, S. Tebar for excellent technical assistance, R. Rycroft for correcting the English version of the manuscript, and the personnel at the Serveis Cientificotècnics, Universitat de Barcelona for DNA sequencing, assistance, and technical advice.

Financial support: This study was supported by the Spanish Government (PB86-0546, SAL-90-0960-CO2, PB94-0865, FIS 99/0036-01, FIS 01/0831, and SAF02-10172) and the European Union (TS2M0058-F and FAIR 6-CT98-4104).

Authors' addresses: Liliana Montoya, Montserrat Gállego, Montserrat Portús, and Roser Fisa, Laboratory of Parasitology, Faculty of Pharmacy, Universitat de Barcelona, Avenida Joan XXIII s/n, 08028 Barcelona, Spain, Telephone: 34-93-4024502, Fax: 34-93-4024504. Béatrice Gavignet and Renaud Piarroux, Santé Environnement Rural Franche-Comté, Université de Franche-Comté, Besançon, France, Telephone: 33-38-166-8068. Jean-Antoine Rioux, Institut de Botanique, Université Montpellier I, Montpellier, France.

\section{REFERENCES}

1. Pratlong F, Rioux JA, Marty P, Faraut-Gambarelli F, Dereure J, Lanotte G, Dedet JP, 2004. Isoenzymatic analysis of 712 strains of Leishmania infantum in the south of France and relationship of enzymatic polymorphism to clinical and epidemiological features. J Clin Microbiol 42: 4077-4082.

2. Gállego M, Pratlong F, Fisa R, Riera C, Rioux JA, Dedet JP, Portús M, 2001. The life-cycle of Leishmania infantum MON77 in the Priorat (Catalonia, Spain) involves humans, dogs and sandflies; also literature review of distribution and hosts of $L$. infantum zymodemes in the Old World. Trans R Soc Trop Med Hyg 95: 269-271.

3. Martín-Sánchez J, Gramiccia M, Di Muccio T, Ludovisi A, Morillas-Márquez F, 2004. Isoenzymatic polymorphism of Leishmania infantum in southern Spain. Trans $R$ Soc Trop Med Hyg 98: 228-232.

4. Pratlong F, Dereure J, Deniau M, Marty P, Faraut-Gambarelli F, Dedet JP, 2002. Enzymatic polymorphism during Leishmanial HIV co-infection: a study of 381 Leishmania strains received between 1986 and 2000 at the international cryobank in Montpellier, France. Ann Trop Med Parasitol 97: S47-S56.

5. Gramiccia M, Gradoni L, Troiani M, 1995. Heterogeneity among zymodemes of Leishmania infantum from HIV-positive patients with visceral leishmaniasis in south Italy. FEMS Microbiol Lett 128: 33-38.

6. Jiménez M, Alvar J, Tibayrenc M, 1997. Leishmania infantum is clonal in AIDS patients too: epidemiological implications. AIDS 11: 569-573.

7. Toledo A, Martín-Sánchez J, Pesson B, Sanchiz-Marín C, Morillas-Márquez F, 2002. Genetic variability within the species Leishmania infantum by RAPD. A lack of correlation with zymodeme structure. Mol Biochem Parasitol 119: 257-264.

8. Hide M, Bañuls AL, Tibayrenc M, 2001. Genetic heterogeneity and phylogenetic status of Leishmania (Leishmania) infantum zymodeme MON-1: epidemiological implications. Parasitology 123: 425-432.

9. Hanafi R, Barhoumi M, Ali SB, Guizani I, 2001. Molecular analyses of Old World Leishmania RAPD markers and development of a PCR assay selective for parasites of the L. donovani species complex. Exp Parasitol 98: 90-99.

10. Gangneux JP, Menotti J, Lorenzo F, Sarfati C, Blanche H, Bui H, Pratlong F, Garin YJ, Derouin F, 2003. Prospective value of PCR amplification and sequencing for diagnosis and typing of Old World Leishmania infections in an area of nonendemicity. J Clin Microbiol 41: 1419-1422.

11. Guerbouj S, Guizani I, Speybroeck N, Le Ray D, Dujardin JC, 
2001. Genomic polymorphism of Leishmania infantum: a relationship with clinical pleomorphism? Infect Genet Evol 1: 4959.

12. Oliveira RP, Broude NE, Macedo AM, Cantor CR, Smith CL, Pena SD, 1998. Probing the genetic population structure of Trypanosoma cruzi with polymorphic microsatellites. Proc Natl Acad Sci U S A 95: 3776-3780.

13. Oliveira RP, Melo AI, Macedo AM, Chiari E, Pena SD, 1999. The population structure of Trypanosoma cruzi: expanded analysis of 54 strains using eight polymorphic CA-repeat microsatellites. Mem Inst Oswaldo Cruz 94: 65-70.

14. Macedo AM, Pimenta JR, de Aguiar RS, Melo AI, Chiari E, Zingales B, Pena SD, Oliveira RP, 2001. Usefulness of microsatellite typing in population genetic studies of Trypanosoma cruzi. Mem Inst Oswaldo Cruz 96: 407-413.

15. Russell R, Iribar MP, Lambson B, Brewster S, Blackwell JM, Dye C, Ajioka JW, 1999. Intra and inter-specific microsatellite variation in the Leishmania subgenus Viannia. Mol Biochem Parasitol 103: 71-77.

16. Schwenkenbecher JM, Fröhlich C, Gehre F, Schnur LF, Schönian $\mathrm{G}, 2004$. Evolution and conservation of microsatellite markers for Leishmania tropica. Infect Genet Evol 4: 99-105.

17. Kuhls K, Mauricio IL, Pratlong F, Presber W, Schönian G, 2005. Analysis of ribosomal DNA internal transcribed spacer sequences of the Leishmania donovani complex. Microbes Infect 7: $1224-1234$

18. Ochsenreither S, Kuhls K, Schaar M, Presber W, Schönian G, 2006. Multilocus microsatellite typing as a new tool for discrimination of Leishmania infantum MON-1 strains. J Clin Microbiol 44: 495-503.

19. Costa JM, Dardé ML, Assouline B, Vidaud M, Bretagne S, 1997. Microsatellite in the beta-tubulin gene of Toxoplasma gondii as a new genetic marker for use in direct screening of amniotic fluids. J Clin Microbiol 35: 2542-2545.

20. Ajzenberg D, Bañuls AL, Tibayrenc M, Dardé ML, 2002. Microsatellite analysis of Toxoplasma gondii shows considerable polymorphism structured into two main clonal groups. Int $J$ Parasitol 32: 27-38.

21. Bulle B, Millon L, Bart JM, Gállego M, Gambarelli F, Portús M, Schnur L, Jaffe CL, Fernández-Barredo S, Alunda JM, Piarroux R, 2002. Practical approach for typing strains of Leishmania infantum by microsatellite analysis. J Clin Microbiol 40: 3391-3397.

22. Rioux JA, Guilvard E, Gállego J, Moreno G, Pratlong F, Portús M, Rispail P, Gállego M, Bastien P, 1986. Intervention simultanée de Phlebotomus ariasi Tonnoir, 1921 et $P$. perniciosus Newstead 1911 dans un même foyer. Infestations par deux zymodèmes syntopiques. A propos d'une enquête en Catalogne (Espagne). Rioux JA, eds. Leishmania: Taxonomie et Phylogenèse. Montpellier: I.M.E.E.E., 439-444.

23. Fisa R, Gállego M, Castillejo S, Aisa MJ, Serra T, Riera C, Carrió J, Gállego J, Portús M, 1999. Epidemiology of canine leishmaniosis in Catalonia (Spain). The example of the Priorat focus. Vet Parasitol 83: 87-97.

24. Bolòs O, Vigo J, 1984. Flora dels Països Catalans. Volume I. Barcelona, Spain: Barcino.

25. Portús M, Gállego M, Riera C, Fisa R, Aisa MJ, Botet J, Carrió J, Castillejo S, Iniesta L, López P, Montoya L, Muñoz C, Serra T, Gállego J, 2007. A review of human and canine leshmaniosis in Catalonia, and associated vector distribution. Rev Iber Parasitol 66: 7 pp.

26. Guilvard E, Gállego M, Moreno G, Fisa R, Rispail P, Pratlong F, Martínez-Ortega E, Gállego J, Rioux JA, 1996. Infestation naturelle de Phlebotomus ariasi et Phlebotomus perniciosus (Diptera, Psychodidae) par Leishmania infantum (Kinetoplastida-Trypanosomatidae) en Catalogne (Espagne). Parasite 3: 191-192.

27. Rioux JA, Lanotte G, Serres E, Pratlong F, Bastien P, Périères J, 1990. Taxonomy of Leishmania. Use of isoenzymes. Suggestions for a new classification. Ann Parasitol Hum Comp 65: $111-125$.

28. Goudet J, 1995. FSTAT, A Program to Estimate and Test Gene Diversities and Fixation Indices (version 2.9.3.2.). Available from http://www.unil.ch/izea/softwares/fstat.html
29. Rohlf FJ, 1993. Numerical Taxonomy and Multivariate Analysis System. Version 1.8. Setauket, NY: Exeter Software.

30. Cupolillo E, Brahim LR, Toaldo CB, de Oliveira-Neto MP, de Brito ME, Falqueto A, de Farias Naiff M, Grimaldi G Jr, 2003. Genetic polymorphism and molecular epidemiology of Leishmania (Viannia) braziliensis from different hosts and geographic areas in Brazil. J Clin Microbiol 41: 3126-3132.

31. Jiménez M, Ferrer-Dufol M, Cañavate C, Gutiérrez-Solar B, Molina R, Laguna F, López-Vélez R, Cercenado E, Daudén E, Blázquez J, Ladrón de Guevara C, Gómez J, de la Torre J, Barros C, Altés J, Serra T, Alvar J, 1995. Variability of Leishmania (Leishmania) infantum among stocks from immunocompromised, immunocompetent patients and dogs in Spain. FEMS Microbiol Lett 131: 197-204.

32. Pratlong F, Dedet JP, Marty M, Portús M, Deniau M, Dereure J, Abranches P, Reynes J, Martini A, Lefebvre M, Rioux JA, 1995. Leishmania-human immunodeficiency virus co-infection in the Mediterranean basin: isoenzymatic characterization of 100 isolates of the Leishmania infantum complex. $J$ Infect Dis 172: 323-326.

33. Gállego M, Pratlong F, Riera C, Fisa R, Muñoz C, Dedet JP, Portús M, 2001. Cutaneous leishmaniasis due to Leishmania infantum in the northeast of Spain: the isoenzymatic analysis of parasites. Arch Dermatol 137: 667-668.

34. Portús M, Gállego J, Rioux JA, Pratlong F, Moreno G, Fisa R, Gállego M, Muñoz C, Riera C, Sánchez F, Serra T, 1989. Enzymatic heterogeneity among strains of Leishmania infantum from human visceral and cutaneous leishmaniosis in Catalonia (Spain). Rev Iber Parasitol 49: 287-289.

35. Guilvard E, Rioux JA, Gállego M, Pratlong F, Mahjour J, Martínez-Ortega E, Dereure J, Saddiki A, Martini A, 1991. Leishmania tropica au Maroc. III. Rôle vecteur de Phlebotomus sergenti. A propos de 89 isolats. Ann Parasitol Hum Comp 66: 96-99.

36. Pratlong F, Rioux JA, Dereure J, Mahjour J, Gállego M, Guilvard E, Lanotte G, Périères J, Martini A, Saddiki A, 1991. Leishmania tropica au Maroc. IV. Diversité isoenzymatique intrafocale. Ann Parasitol Hum Comp 66: 100-104.

37. Riera C, Fisa R, Udina M, Gállego M, Portús M, 2004. Detection of Leishmania infantum cryptic infection in asymptomatic blood donors living in an endemic area (Eivissa, Balearic Islands, Spain) by different diagnostic methods. Trans $R$ Soc Trop Med Hyg 98: 102-110.

38. le Fichoux Y, Quaranta JF, Aufeuvre JP, Lelievre A, Marty P, Suffia I, Rousseau D, Kubar J, 1999. Occurrence of Leishmania infantum parasitemia in asymptomatic blood donors living in an area of endemicity in southern France. J Clin Microbiol 37: 1953-1957.

39. Rioux JA, Albaret JL, Houin R, Dedet JP, Lanotte G, 1968. Écologie des leishmanioses dans le sud de la France. 2. Les réservoirs selvatiques. Infestation spontanée du renard (Vulpes vulpes L.). Ann Parasitol Hum Comp 43: 421-428.

40. Abranches P, Conceiçao-Silva FM, Ribeiro MMS, Lopes FJ, Gomes LT, 1983. Kala-azar in Portugal. IV. The wild reservoir: the isolation of Leishmania from a fox. Trans $R$ Soc Trop Med Hyg 77: 420-421.

41. Gállego M, 2004. Zoonosis emergentes por patógenos parásitos: las leishmaniosis. Rev Sci Tech 23: 661-676.

42. Portús M, Gállego M, Riera C, Aisa MJ, Fisa R, Castillejo S, 2002. Wild and domestic mammals in the life cycle of Leishmania infantum in Southwest Europe. A literature review and studies performed in Catalonia (Spain). Rev Iber Parasitol 62: $72-76$.

43. Costa Durao JF, Rebelo E, Peleteiro MC, Correia JJ, Simoes G, 1994. Primeiro caso de leishmaniose em gato doméstico (Felis catus domesticus) detectado em Portugal (Concelho de Sesimbra). Rev Port Ciênc Vet 89: 140-144.

44. Poli A, Abramo F, Barsotti P, Leva S, Gramiccia M, Ludovisi A, Mancianti F, 2002. Feline leishmaniosis due to Leishmania infantum in Italy. Vet Parasitol 106: 181-191.

45. Solano-Gallego L, Fernández-Bellon H, Serra P, Gállego M, Ramis A, Fondevila D, Ferrer L, 2003. Cutaneous leishmaniosis in three horses in Spain. Equine Vet J 35: 320-323.

46. Morillas Márquez F, Benavides Delgado I, González Castro J, Reyes Magana A, Valero López A, 1985. Découverte de 
Leishmania sp dans des Rattus rattus de la province de Granade (Espagne). Ann Parasitol Hum Comp 60: 768-770.

47. Bettini S, Pozio E, Gradoni L, 1980. Leishmaniasis in Tuscany (Italy) II. Leishmania from wild Rodentia and Carnivora in a human and canine leishmaniasis focus. Trans $R$ Soc Trop Med Hyg 74: 77-83.

48. Gramiccia M, Gradoni L, Angelici MC, 1989. Epidemiology of Mediterranean leishmaniasis by Leishmania infantum: izoenzyme and kDNA analysis for the identification of parasites from man, vectors, and reservoirs. Hart DJ, ed. Leishmaniasis. The Current Status and New Strategies for Control. New York: Plenum Press, NATO ASI Series, Series A 163: 21-37.

49. Barrios MA, Rodriguez N, Feliciangeli DM, Ulrich M, Telles S, Pinardi ME, Convit J, 1994. Coexistence of two species of
Leishmania in the digestive tract of the vector Leishmania ovallesi. Am J Trop Med Hyg 51: 669-675.

50. Pratlong F, Portús M, Rispail P, Moreno G, Bastien P, Rioux JA, 1989. Présence simultanée chez le chien de deux zymodèmes du complexe Leishmania infantum. Ann Parasitol Hum Comp 64: 312-314.

51. Cortés P, Cardeñosa N, Romaní J, Gállego M, Muñoz C, Barrio JL, Riera C, Portús M, 1997. Oral leishmaniasis in an HIVpositive patient caused by two different zymodemes of Leishmania infantum. Trans $R$ Soc Trop Med Hyg 91: 438-439.

52. Antoniou M, Doulgerakis C, Pratlong F, Dedet JP, Tselentis Y, 2004. Short report: treatment failure due to mixed infection by different strains of the parasite Leishmania infantum. Am J Trop Med Hyg 71: 71-72. 